\title{
Vital capacity and patient controlled sevoflurane inhalation result in similar induction characteristics
}

\author{
[L'inbalation de sévoflurane à capacité vitale et l'inhalation autocontrôlée \\ induisent l'anesthésie de façon similaire]
}

Suntheralingam Yogendran FrCPC, Atul Prabhu FrCA, Ayman Hendy MBBs, Glenn McGuire MD, Charles Imarengiaye MBBS, Jean Wong FRCPC, Frances Chung FRCPC

Purpose: To compare patient controlled inhalational induction ( $\mathrm{PCl}$ ) with the most commonly used sevoflurane induction technique, vital capacity inhalational induction ( $\mathrm{VCl}$ ).

Methods: Following approval of the Research Ethics Board, 124 outpatients undergoing knee arthroscopy were randomly assigned to receive either $\mathrm{PCl}$ or $\mathrm{VCl}$ sevoflurane followed by laryngeal mask airway (LMA) insertion and sevoflurane maintenance. In the PCl group, the circle circuit was not primed. The patients were asked to hold the facemask themselves and breathe normally with sevoflurane $8 \%$ in oxygen at a flow rate of $4 \mathrm{~L} \cdot \mathrm{min}^{-1}$. In the $\mathrm{VCl}$ group, the circle circuit was primed and patients were asked to take vital capacity breaths with sevoflurane $8 \%$ at an oxygen flow rate of $8 \mathrm{~L} \cdot \mathrm{min}^{-1}$. The LMA was inserted as soon as the patient's jaw was relaxed. Time from induction to LMA insertion was recorded and insertion conditions rated. The amount of sevoflurane used for LMA insertion was calculated. Vital signs were monitored at oneminute intervals until ten minutes after LMA insertion.

Results: Demographic data were comparable. There were no differences with respect to LMA insertion time $(\mathrm{PCl}-3.4$ min vs $\mathrm{VCl}$ - $3.3 \mathrm{~min}$ ), laryngospasm ( $\mathrm{PCl}$ - 7\% vs $\mathrm{VCl}$ - 5\%), mean arterial pressure, heart rate, $\mathrm{SaO}_{2}$ as well as patient's overall satisfaction.

Conclusion: $\mathrm{PCl}$ was comparable to $\mathrm{VCl}$ in sevoflurane induction with respect to the speed of induction, side effects during induction and patient satisfaction. However, $\mathrm{PCl}$ requires no special training and is widely applicable to all patient populations.
Objectif : Comparer l'induction par inhalation autocontrôlée (IAC) avec l'induction par inhalation à capacité vitale (ICV), technique la plus utilisée.

Méthode : Avec l'accord du Comité d'éthique en recherche, 124 patients répartis au hasard pour une arthroscopie du genou en chirurgie ambulatoire ont reçu une IAC ou une ICV au sévoflurane, suivie de l'insertion d'un masque laryngé (ML) et du maintien de l'anesthésie avec du sévoflurane. Le circuit cercle n'a pas été instauré pour I'IAC. Les patients devaient tenir eux-mêmes le masque et respirer normalement un mélange d'oxygène et de sévoflurane à $8 \%$ selon un débit de $4 \mathrm{~L} \cdot \mathrm{min}^{-1}$. Pour l'ICV, le circuit cercle a été amorcé et les patients inspiraient à capacité vitale un mélange identique de gaz à $8 \mathrm{~L} \cdot \mathrm{min}^{-1}$. Le $\mathrm{ML}$ a été inséré aussitôt la mâchoire relâchée. Le temps écoulé entre l'induction et l'insertion du masque a été noté et les conditions d'insertion cotées. Le sévoflurane utilisé pour l'insertion du ML a été quantifié. Les signes vitaux ont été enregistrés à une minute d'intervalle jusqu'à dix minutes après l'insertion du ML.

Résultats : Les caractéristiques des patients étaient comparables. II n'y a pas eu de différence intergroupe quant au temps précédant l'insertion du ML (IAC - 3,4 min vs ICV - 3,3 min), la présence de laryngospasme (IAC - $7 \%$ vs ICV - $5 \%$ ), la tension artérielle moyenne, la fréquence cardiaque, la $\mathrm{SaO}_{2}$ et la satisfaction des patients.

Conclusion : L'IAC a été comparable à l'ICV pour l'induction au sévoflurane quant à la rapidité de l'induction, aux effets secondaires pendant l'induction et à la satisfaction du patient. Toutefois, l'IAC n'exige pas de formation spéciale et convient à tous les patients.

From the Department of Anesthesia, Toronto Western Hospital, University Health Network, University of Toronto, Toronto, Ontario, Canada.

Address correspondence to: Dr. Suntheralingam Yogendran, Department of Anesthesia, EC 2-046, Toronto Western Hospital,

399 Bathurst Street, Toronto, Ontario M5T 2S8, Canada. Phone: 416-603-5118; Fax: 416-603-6494;

E-mail: Suntheralingam.yogendran@uhn.on.ca

Accepted for publication January 29, 2004.

Revision accepted August 2, 2004.

CAN J ANESTH 2005/52: 1 / pp 45-49 
I NTRAVENOUS induction is the standard method of induction of anesthesia in adults, but the recent introduction of newer inhalational anesthetic agents has made inhalational induction of anesthesia an attractive alternative. ${ }^{1}$ Inhalational induction allows the use of a single agent for both induction and maintenance. Sevoflurane is a relatively recently released volatile anesthetic agent which has already proven itself as an agent of choice for inhalational induction of anesthesia. ${ }^{2}$ It has important properties (low blood: gas solubility coefficient of 0.69 and minimal airway irritation), which make it close to the ideal anesthetic gas. ${ }^{3}$

Inhalational induction techniques using sevoflurane include vital capacity induction (VCI) in which the patient is asked to take a deep breath and hold it for as long as possible then breathe out to residual volume. ${ }^{4}$ The other possible technique is patient controlled induction (PCI), in which the patient breathes normal tidal volume breaths and holds the anesthesia mask himself/herself. VCI was the first technique to be introduced with the emergence of sevoflurane but the high volume of sevoflurane required with this technique has restricted its use. At present, only two studies have compared these techniques with respect to the time of loss of response to command, loss of eyelash reflex and ease of laryngeal mask airway (LMA) insertion. Both studies found no difference between the two techniques. ${ }^{5,6}$ However, one author ${ }^{5}$ used a modified Bain circuit with $33 \%$ oxygen $\left(\mathrm{O}_{2}\right)$ at a total flow of $6 \mathrm{~L} \cdot \mathrm{min}^{-1}$ [ $2 \mathrm{~L}$ of $\mathrm{O}_{2}$ and $4 \mathrm{~L}$ of nitrous oxide $\left(\mathrm{N}_{2} \mathrm{O}\right) /$ minute]. The other author used sevoflurane in a mixture of $\mathrm{N}_{2} \mathrm{O}$ ans $\mathrm{O}_{2}$ in a ration of 2:1 with the total fresh gas flow of $8 \mathrm{~L} \cdot \mathrm{min}^{-1}$ using a circle system. ${ }^{6}$ We chose induction with $100 \% \mathrm{O}_{2}$ to increase the margin of safety in case of desaturation caused by laryngospasm or underlying pulmonary conditions.

We designed this prospective study of sevoflurane inhalational induction, using $\mathrm{O}_{2}$ as carrier gas and circle system, to compare VCI with PCI with respect to time needed for LMA insertion, ease of LMA insertion, patient satisfaction, and postoperative pain, nausea and vomiting.

\section{Methods}

Approval of the hospital's Research Ethics Committee and written informed consent were obtained. One hundred and twenty four patients were included in this prospective randomized study. The inclusion criteria were ASA grade I or II patients between 18 to 65 yr of age scheduled for ambulatory knee arthroscopy. Exclusion criteria included obesity (body mass index > 35 ), symptomatic regurgitation or hiatus hernia, the inability to understand the vital capacity technique and pregnancy.

One hour before surgery, patients were premedicated with oral naprosyn $500 \mathrm{mg}$ to reduce intraoperative and postoperative analgesic requirements. Patients were randomized into two groups: PCI or VCI according to a computer generated block randomization table. Instructions on both techniques were given to all patients before surgery but patients only knew what group they were randomized to in the operating room.

Upon arrival in the operating room, standard monitors were applied: electrocardiogram (lead II), noninvasive blood pressure monitoring and pulse oximetry $\left(\mathrm{SaO}_{2}\right)$. Bispectral index (BIS) electrodes were applied to the forehead before the induction of anesthesia in order to obtain the preanesthetic value. A circle breathing system was used in both groups. Intravenous normal saline was started through a 20gauge cannula. Patients received no sedative or narcotics before induction.

In the PCI group, patients were asked to hold the mask and breathe normal tidal volume breaths. Fresh gas flow (FGF) was $4 \mathrm{~L}$ of $\mathrm{O}_{2}$ with a dial setting of $8 \%$ sevoflurane. The circuit was not primed. In the VCI group, the anesthetic circuit was first primed with sevoflurane by completely collapsing the 2 -L bag twice initially and occluding the $\mathrm{Y}$ piece with gauze. The circuit was flushed with $8 \mathrm{~L}$ of $\mathrm{O}_{2}$ with an $8 \%$ sevoflurane dial setting while keeping the adjustable pressure-limiting valve closed. The priming endpoint was an end-tidal sevoflurane concentration $>6 \%$. The time taken to prime the circuit (approximately $60 \mathrm{sec}$ ) was noted and was taken into account for later calculation of total sevoflurane used in both techniques.

Once in the operating room, VCI patients were instructed to practice one vital capacity breathing room air. The anesthesia mask was applied and patients were asked to take a deep breath from the residual lung volume and instructed to hold the breath as long as possible. They were encouraged to take vital capacity breaths until unconsciousness occurred. The following clinical signs of loss of consciousness were evaluated every ten seconds: loss of response to command (patients were asked to open their eyes), loss of eyelash reflex, and loss of handgrip. When the patient became unconscious, the FGF was reduced to $4 \mathrm{~L} \cdot \mathrm{min}^{-1}$ to prevent excessive use of sevoflurane.

Adverse events (coughing, breath holding, laryngeal spasm, movements, and excitement) were assessed by a research assistant during induction and recorded in both groups. Treatment of these side effects included manual ventilation to increase anes- 
thesia depth. If this was insufficient, $50 \mathrm{mg}$ incremental boluses of propofol were administered.

In both groups, the following variables were collected by a research assistant: heart rate, blood pressure, $\mathrm{SaO}_{2}, \mathrm{BIS}$ readings, and end-tidal sevoflurane concentration every minute for the first ten minutes postinduction, then every three minutes for the next ten minutes.

LMA insertion was attempted every $30 \mathrm{sec}$ after loss of consciousness and time of successful placement was recorded. Anesthesiologists were asked to evaluate the mask insertion as smooth (full insertion), partial (gagging/coughing) or poor (need for repositioning). The number of attempts at LMA insertion was recorded for every patient. After successful LMA insertion, anesthesia was maintained in both groups with a combination of $\mathrm{O}_{2}$ and $\mathrm{N}_{2} \mathrm{O}$ (1L:1L). Sevoflurane concentration was adjusted to keep the end-tidal sevoflurane concentration between 1.5 to $2 \%$ and BIS around 50 .

Boluses of $12.5 \mu \mathrm{g}$ fentanyl were used to maintain respiratory rate between 10 to 20 breaths. $\mathrm{min}^{-1}$. At the end of surgery, the surgeons infiltrated $20 \mathrm{~mL}$ of $0.5 \%$ plain bupivacaine into the knee joint. The anesthesiologist then discontinued $\mathrm{N}_{2} \mathrm{O}$ and sevoflurane and increased $\mathrm{O}_{2}$ flow to $8 \mathrm{~L} \cdot \mathrm{min}^{-1}$. The LMA was removed when patients opened their eyes or when they coughed.

The volume of anesthetic vapour was calculated according to the following formula:

$$
\begin{aligned}
& \text { Volume of total sevoflurane used }=\text { PFTM } / 2412 \times \text { day }^{7} \\
& -\mathrm{P}=\text { Vaporizer concentration }(\%) ; \\
& -\mathrm{F}=\text { Fresh gas flow }\left(\mathrm{L} \cdot \mathrm{min}^{-1}\right) ; \\
& -\mathrm{T}=\text { Duration of anesthesia }(\mathrm{min}) ; \\
& -\mathrm{M}=\text { molecular weight of sevoflurane; } \\
& -\mathrm{d}=\text { density }\left(\mathrm{g} \cdot \mathrm{mL}^{-1}\right) .
\end{aligned}
$$

After the end of surgery, patients were transferred to the postanesthesia care unit (PACU) and were asked to answer a standardized oral questionnaire including visual analogue scale (VAS) for pain and nausea. Pain in the PACU was treated with fentanyl and/or with two tablets of acetaminophen $500 \mathrm{mg}$, which were given at the discretion of the nurse as per routine PACU order protocol. Nausea and vomiting were treated with $1 \mathrm{mg}$ of granisetron intravenously before discharge from the PACU. A research assistant asked the patients about the smell of sevoflurane, their satisfaction about induction and emergence. All patients were contacted by telephone to answer a standardized questionnaire $24 \mathrm{hr}$ postoperatively.
TABLE I Demographic characteristics and intraoperative variables

\begin{tabular}{lll}
\hline & $P C I$ & $V C I$ \\
\hline$n$ & 63 & 61 \\
Age $(\mathrm{yr})$ & $45 \pm 16$ & $45 \pm 13$ \\
Weight $(\mathrm{kg})$ & $81 \pm 18$ & $80 \pm 15$ \\
Height $(\mathrm{cm})$ & $172 \pm 10$ & $171 \pm 8$ \\
Duration of anesthesia $(\mathrm{min})$ & $43 \pm 16$ & $42 \pm 11$ \\
Duration of surgery $(\mathrm{min})$ & $32 \pm 17$ & $30 \pm 9$ \\
Intraoperative fentanyl $(\mu \mathrm{g})$ & $72 \pm 25$ & $73 \pm 28$ \\
Intraoperative fluids $(\mathrm{mL})$ & $641 \pm 179$ & $632 \pm 192$ \\
\hline
\end{tabular}

$\mathrm{PCI}=$ patient controlled induction; $\mathrm{VCI}=$ vital capacity induction. Values are expressed as mean $\pm \mathrm{SD}$. No significant difference between groups.

TABLE II Induction times and LMA insertion characteristics

\begin{tabular}{lll}
\hline & $P C I$ & $V C I$ \\
\hline Loss of eyelash reflex (min) & $1.5 \pm 0.6$ & $1.5 \pm 0.6$ \\
Loss of response to command (min) & $1.4 \pm 0.2$ & $1.5 \pm 0.9$ \\
Time to LMA insertion (min) & $3.4 \pm 1.1$ & $3.3 \pm 0.9$ \\
Mean sevoflurane ET\% before LMA & $4.22 \pm 0.97$ & $3.97 \pm 1.0$ \\
$\begin{array}{l}\text { Sevoflurane used for LMA } \\
\text { insertion (mL) }\end{array}$ & $4.43 \pm 1.5^{*}$ & $8.00 \pm 2.8$ \\
$\begin{array}{l}\text { BIS reading at three minutes } \\
\text { BIS reading at four minutes }\end{array}$ & $50 \pm 26$ & $45 \pm 22$ \\
$\begin{array}{l}\text { Successful LMA insertion after } \\
\text { first attempt }\end{array}$ & $88 \% 23$ & $40 \pm 19$ \\
$\begin{array}{l}\text { Successful LMA insertion after } \\
\text { second attempt }\end{array}$ & $12 \%$ & $86 \%$ \\
$\begin{array}{l}\text { Successful LMA insertion after } \\
\text { third attempt }\end{array}$ & 0 & $10 \%$ \\
\hline
\end{tabular}

LMA = laryngeal mask airway; PCI = patient controlled induction; $\mathrm{VCI}=$ vital capacity induction; $\mathrm{ET}=$ end-tidal; $\mathrm{BIS}=$ bispectral index. Values are expressed as mean $\pm \mathrm{SD}$. ${ }^{*} P<0.05$.

\section{Statistics}

The number of patients required was based on data from a previous study. ${ }^{5}$ Sample size was calculated assuming an alpha value of 0.05 and a power of 0.8 . If the mean difference for time taken to insert the LMA between the PCI and VCI groups is about $15 \%$, the anticipated sample size will be 60 patients in each group. A clinically significant difference in the time needed for LMA insertion would be $30 \mathrm{sec}$.

Chi-square, Mann-Whitney and unpaired twotailed Students $t$ tests were used as appropriate. A $P<$ 0.05 was considered as statistically significant.

\section{Results}

One hundred and twenty four patients were enrolled in this study, 63 in the PCI group and 61 in the VCI group. The two treatment groups were comparable with respect to demographic characteristics, ASA 


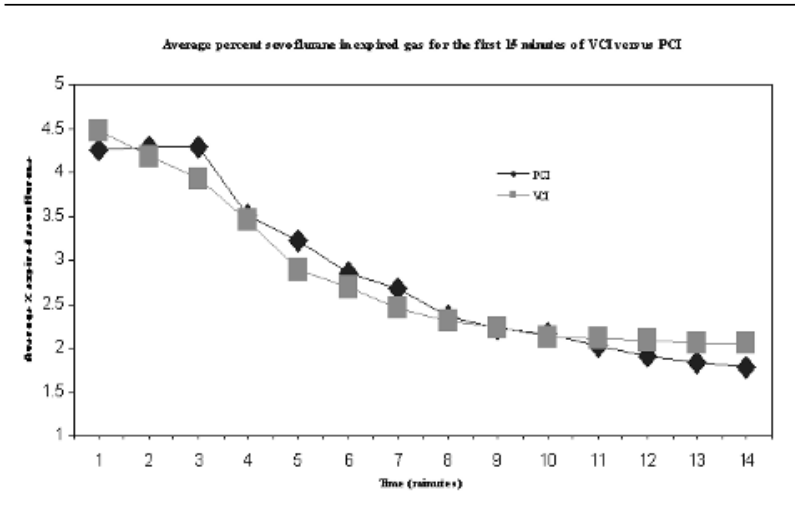

FIGURE 1 Average percent of anesthetic gas in expired gas for the first $15 \mathrm{~min}$ of vital capacity induction (VCI) vs patient controlled induction (PCI).

physical status, duration of surgery and duration of anesthesia (Table I).

Intraoperatively there were no differences between groups regarding the speed of induction as judged by time needed for loss of response to command, loss of eyelash reflex, and successful LMA insertion (Table II). There was no difference in the average percentage of sevoflurane in the expired gas for the first $15 \mathrm{~min}$ (Figure 1). The average volume of sevoflurane used for LMA insertion was significantly higher in the VCI group $(8.0 \pm 2.8 \mathrm{~mL})$ than in the PCI group $(4.4 \pm$ $1.5 \mathrm{~mL}$ ). Average time to LMA insertion was $3.4 \mathrm{~min}$ in the PCI group and $3.3 \mathrm{~min}$ in the VCI group. Average BIS readings for both groups were comparable at three-minute and four-minute intervals (Table II; Figure 2). The incidence of adverse effects during induction was comparable in both groups (Table III). Duration of anesthesia and surgery, intraoperative pain medication and fluid therapy were comparable in both groups (Table I). The VAS score for nausea and the incidence of vomiting were not significantly different between the groups in the early phase of recovery (Table IV). There was no difference in the pain scores or the amount of rescue medication administered in the PACU in both groups. Patient acceptance in regards to smell, induction characteristics and overall satisfaction of both techniques were comparable (Table V).

\section{Discussion}

The question addressed by the present study was whether PCI using sevoflurane is equivalent to VCI with regards to the time needed for LMA placement,
TABLE III Adverse effects during LMA insertion

\begin{tabular}{lll}
\hline & $\begin{array}{l}P C I(\%, n) \\
n=63\end{array}$ & $\begin{array}{l}V C I(\%, n) \\
n=61\end{array}$ \\
\hline LMA insertion without adverse effects & $62 \%(39)$ & $64 \%(39)$ \\
Coughing & $0 \%$ & $2 \%(2)$ \\
Breath holding & $11 \%(7)$ & $6 \%(4)$ \\
Laryngeal spasm & $7 \%(4)$ & $5 \%(3)$ \\
Movement & $11 \%(7)$ & $15 \%(8)$ \\
Excitement & $9 \%(6)$ & $8 \%(5)$ \\
\hline
\end{tabular}

$\mathrm{PCI}=$ patient controlled induction; $\mathrm{VCI}=$ vital capacity induction; LMA = laryngeal mask airway.

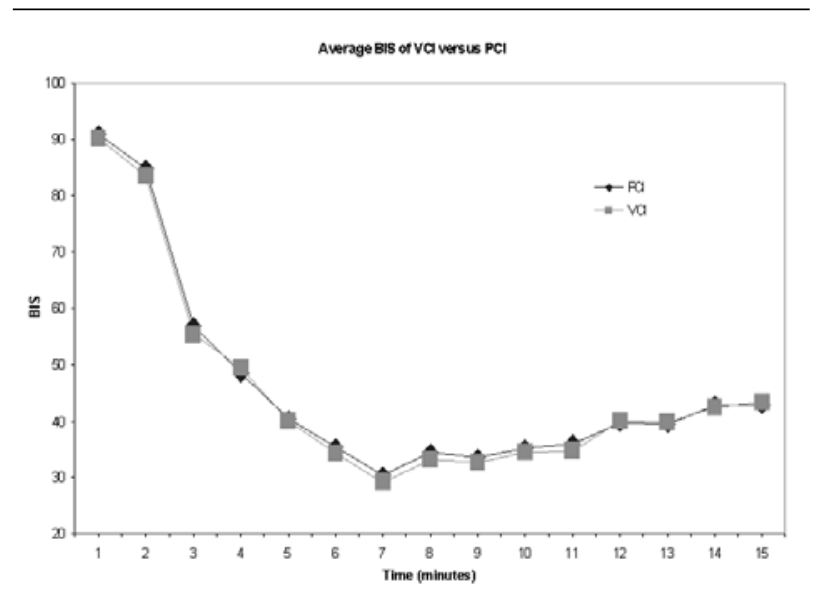

FIGURE 2 Average bispectral index (BIS) reading of vital capacity induction (VCI) vs patient controlled induction (PCI).

smoothness of induction, patient satisfaction with both techniques and side effects. There is a need for patient cooperation and education regarding vital capacity breathing in the VCI technique. There is no need for patient education in the PCI technique. We noted that having the patient practice vital capacity breathing did not lead to hyperventilation and apnea during induction. There was no difference in the incidence of postoperative nausea.

The acceptance of inhalational induction in routine clinical practice in adults depends on smoothness and rapidity of onset of anesthesia, and lack of serious side effects. ${ }^{9}$ Sevoflurane has two attributes that facilitate rapid, smooth inhalational induction: a) a low blood gas solubility; and b) relative absence of pungency. The mean induction time in both groups (PCI and VCI) was comparable, despite priming of the circuit with $8 \%$ sevoflurane and use of vital capacity breaths in the VCI 
TABLE IV Postoperative data

\begin{tabular}{lll}
\hline & $\begin{array}{l}\text { PCI } \\
n=63\end{array}$ & $\begin{array}{l}\text { VCI } \\
n=61\end{array}$ \\
\hline PACU (VAS) pain scales (mean \pm SD) & $4 \pm 0.5$ & $4 \pm 0.3$ \\
PACU pain rescue & 43 & 47 \\
$\quad$ fentanyl (\%) & 93 & 90 \\
$\quad$ acetaminophen (\%) & $0(0-5)$ & $0(0-7)$ \\
PACU nausea VAS: median (range) & $0(0)$ & $2(3.3)$ \\
PACU vomiting: $n(\%)$ & $3(4.8)$ & $4(6.6)$ \\
Antiemetics in PACU: $n(\%)$ & $11(17.5)$ & $16(26.2)$ \\
Nausea at 24 hr: $n(\%)$ &
\end{tabular}

PCI = patient controlled induction; $\mathrm{VCI}=$ vital capacity induction; $\mathrm{PACU}=$ postanesthesia care unit; VAS = visual analogue scale.

TABLE V Patient satisfaction

\begin{tabular}{lll}
\hline & $\begin{array}{l}P C I \\
n=63\end{array}$ & $\begin{array}{l}V C I \\
n=61\end{array}$ \\
\hline $\begin{array}{ll}\text { Smell }[n,(\%)] \\
\text { Pleasant }\end{array} \quad 25(40 \%)$ & $26(43 \%)$ \\
$\quad$ Unpleasant & $16(25 \%)$ & $18(29 \%)$ \\
$\quad$ Undecided & $22(35 \%)$ & $17(28 \%)$ \\
Induction [n, $(\%)]$ & & \\
$\quad$ Smooth & $36(57 \%)$ & $31(51 \%)$ \\
$\quad$ Acceptable & $27(43 \%)$ & $30(49 \%)$ \\
$\quad$ Poor & 0 & 0 \\
Overall experience $[n,(\%)]$ & $9(15 \%)$ & $8(13 \%)$ \\
$\quad$ Excellent & $50(79 \%)$ & $50(82 \%)$ \\
$\quad$ Good & $4(6 \%)$ & $3(5 \%)$ \\
$\quad$ Fair & & \\
\hline
\end{tabular}

$\mathrm{PCI}=$ patient controlled induction; $\mathrm{VCI}=$ vital capacity induction .

group. Theoretically these two factors should hasten the induction of anesthesia in VCI, however, the difference in mean induction time was not significant.

Hall et al. ${ }^{8}$ found that the time to loss of eyelash reflex in VCI was $61 \pm 24 \mathrm{sec}$ after 4 vital capacity breaths from a circuit primed with $8 \%$ sevoflurane and $66 \% \mathrm{~N}_{2} \mathrm{O}$. In our study, the time for the loss of eyelash reflex was longer $(1.5 \pm 0.6 \mathrm{~min}$ in PCI vs $1.5 \pm$ $0.6 \mathrm{~min}$ in VCI). This difference is most probably due to lack of the second gas and concentration effects of $\mathrm{N}_{2} \mathrm{O}$, which we did not use during induction.

Other important factors to be considered in inhalational induction are the volume of the anesthetic gas used and possible pollution of the operating room atmosphere. In this regard, PCI is superior to VCI because priming of the circuit may be responsible for increase of operating room pollution. The average amount of sevoflurane used for LMA insertion was 8 $\mathrm{mL}$ in the VCI group, almost double the amount used in the PCI group $(4.43 \mathrm{~mL})$. Hall et al. ${ }^{8}$ and Baker et $a l .{ }^{5}$ have both described $6 \mathrm{~L}$ of FGF to prime the circuit. The difference in volume of sevoflurane in both PCI and VCI techniques would have been small if we had primed the circuit with lower FGF.

Ambulatory surgery requires a good selection of patients and appropriate care postoperatively. One of the major criteria to determine the readiness for discharge is the absence of postoperative nausea and both techniques had low incidence of this adverse event. In conclusion, the use of PCI is equivalent to VCI with regards to speed of induction, side effects during induction and patient satisfaction. However PCI requires no specific patient training.

\section{Acknowledgement}

We acknowledge the teaching of Dr. Bevin Bart, Calgary, in the patient controlled inhalation induction technique.

\section{References}

1 Ti LK, Pua HL, Lee TL. Single vital capacity inhalational anaesthetic induction in adults-isoflurane vs sevoflurane. Can J Anaesth 1998; 45: 949-53.

2 Smith I, Nathanson M, White PF. Sevoflurane-a longawaited volatile anaesthetic. Br J Anaesth 1996; 76 : 435-45.

3 Strum DP, Eger EI II. Partition coefficients for sevoflurane in human blood, saline, and olive oil. Anesth Analg 1987; 66: 654-6.

4 Philip BK, Lombard LL, Roaf ER, Drager LR, Calalang I, Philip JH. Comparison of vital capacity induction with sevoflurane to intravenous induction with propofol for adult ambulatory anesthesia. Anesth Analg 1999; 89: 623-7.

5 Baker CE, Smith I. Sevoflurane: a comparison between vital capacity and tidal breathing techniques for the induction of anaesthesia and laryngeal mask airway placement. Anaesthesia 1999; 54: 841-4.

6 Yurino $M$, Kimura $H$. Induction of anesthesia with sevoflurane, nitrous oxide and oxygen: a comparison of spontaneous ventilation and vital capacity rapid inhalation induction (VCRII) techniques. Anesth Analg 1993; 76: 598-601.

7 Dion P. The cost of anaesthetic vapours (Letter). Can J Anaesth 1992; 39: 633-4.

8 Hall JE, Stewart JI, Harmer M. Single-breath inhalation induction of sevoflurane anaesthesia with and without nitrous oxide: a feasibility study in adults and comparison with an intravenous bolus of propofol. Anaesthesia 1997; 52: 410-5. 